\title{
Subtraction as interpolated activity in short-term retention
}

\section{MARCER, DEPARTMENT OF PSYCHOLOGY, UNIVERSITY OF SOUTHAMPTON, England. ${ }^{1}$}

The maximum rate at which each of eleven Ss could perform a subtraction task was determined. Subtraction was then used as the interpolated activity in a short-term retention experiment. The required subtraction rate was varied to give three experimental conditions-equal to, less than, or greater than the $S$ 's maximum. Most forgetting occurred when the required rate equalled the $S$ 's maximum rate.

The typical short-term retention experiment requires the recall of a short message after a brief interval, during which the $S$ is usually occupied with performing a continuous subtraction task. The data from such experiments are usually reported in the form of mean recall scores from a group of Ss. With the exception of a set of experiments reported by Talland (1967), little attention seems to have been paid to the efficiency with which the $S$ performs the subtraction task. In most studies the required substraction rate has been constant for all Ss, usually one or two subtractions per second. It is obvious that Ss will vary in their ability to perform the subtraction at the required rate, and a given group of Ss can be divided into three sub-groups: (1) those who could, if necessary, perform at a rate greater than that required (2) those who are just able to maintain the required rate; and (3) those who are unable to maintain the required rate.

As the role of interpolated activity is to prevent rehearsal, it is possible to make predictions about the amount of forgetting which will occur in the three groups. The first group will be able to perform the subtraction efficiently, and still have time to rehearse the stimulus. This should produce less forgetting than in the second group, where rehearsal of the stimulus will be incompatible with efficient subtraction. It is less easy to make predictions about the third group. Ss might maintain their maximum subtraction rate, even though this is less than the required rate. In this case the recall scores of Groups 2 and 3 should not differ. Alternatively the $S$ might find the subtraction task so difficult that he elects to concentrate on rehearsing the stimulus.

The experiment reported here was designed to examine these suggestions.

Method. The Ss were eleven undergraduates, each of whom attended two experimental sessions. In the first session the Ss were told that they were to take part in an experiment to test their ability to perform a simple subtraction task. This consisted of subtracting $3 \mathrm{~s}$ or $4 \mathrm{~s}$ from a three digit number, in time to a metronome. The $S$ was repeatedly urged to try to increase his rate of subtraction, until a point was reached when any further increase produced errors. The time taken to establish this rate was usually about $15 \mathrm{~min}$.

The second session occurred on the day after the first session, and consisted of a short-term retention experiment. Prior to this experiment the $S$ was given practice at subtraction until his maximum rate could be maintained without error. Recall of trigram stimuli was then measured under four conditions: (1) with the metronome set at the S's maximum subtraction rate; (2) and (3) with the metronome set at a rate either $25 \%$ faster or $25 \%$ slower than the S's maximum subtraction rate; and (4) a control condition in which no interpolated activity was performed.

The stimuli were $20 \mathrm{CCC}$ trigrams, presented in a memory drum for $1 \mathrm{sec}$. Following the stimulus, a three digit number appeared which the $\mathrm{S}$ repeated before commencing the subtraction task. All Ss received a block of five syllables under each condition. Syllables were randomized across blocks, and the order in which subtraction rates were required was randomized across Ss. The Ss were informed when a different rate of subtraction was required. The retention interval was $18 \mathrm{sec}$ with a $14 \mathrm{sec}$ recall interval. Each $\mathrm{S}$ received five practice trials. The whole of this session was recorded on magnetic tape.

Results. Responses were scored by a letter-order criterion. The proportion of letters correctly recalled in their correct position for the four conditions were: (1) control $=100 \% ;(2)$ required rate equal to maximum rate $=55.7 \%$; (3) required rate slower than maximum rate $=69.0 \%$; and $(4)$ required rate faster than maximum rate $=68.4 \%$.

Omitting the control condition, analysis of variance showed significant differences for Ss $(p<.01)$ and treatments $(p<.025)$.

Discussion. The results indicate quite clearly that most forgetting occurred when the $S$ was asked to subtract at his maximum rate. The finding that forgetting decreases when a $S$ is asked to attempt to subtract at a rate which is greater than his maximum suggests that the $S$ performs at a rate which is below his maximum, allowing time to rehearse the stimulus. Examination of the tape recording of the learning experiment supports this suggestion. It was found that in the fast subtraction condition Ss performed at a rate which was on average $32 \%$ less than the required rate. This means that asking a $S$ to subtract at a rate which is above his maximum results in a performance rate which is, in fact, less than his maximum.

The suggestion that a slow rate of subtraction permits rehearsal and hence aids recall seems to be contrary to the findings reported by Talland (1967), who found that slow subtraction was usually associated with poor recall. There is, however, a difference in the design of the two experiments. Talland compared the recall scores of Ss who could subtract at the required rate with those who could not. The experiment just reported compared the recall scores of the same $\mathrm{S}$ performing at different rates.

The findings just reported indicate that if a constant subtraction rate is employed in a short-term retention study, some variability in the recall data will arise from differences in the ability of Ss to subtract. A more accurate estimate of treatment effects will be obtained by determining the optimum rate of subtraction for each $S$. This method is particularly desirable when the problem under investigation precludes a repeated measures design.

\section{REFERENCES}

TALLAND, G. A. Short-term memory with interpolated activity. J. verbal Learn. verbal Behav., 1967, 6.

NOTE

1. Now at Sir John Cass College, London, E.C.3. 